\title{
Implicit Coupling Approach for Simulation of Charring Carbon Ablators
}

\author{
Yih-Kanq Chen", \\ NASA Ames Research Center, Moffett Field, CA 94035-1000 \\ and \\ Tahir Gökçen ${ }^{\dagger}$ \\ ERC, Inc., NASA Ames Research Center, Moffett Field, CA 94035-1000
}

This study demonstrates that coupling of a material thermal response code and a flow solver with nonequilibrium gas/surface interaction for simulation of charring carbon ablators can be performed using an implicit approach. The material thermal response code used in this study is the three-dimensional version of Fully Implicit Ablation and Thermal response program, which predicts charring material thermal response and shape change on hypersonic space vehicles. The flow code solves the reacting Navier-Stokes equations using Data Parallel Line Relaxation method. Coupling between the material response and flow codes is performed by solving the surface mass balance in flow solver and the surface energy balance in material response code. Thus, the material surface recession is predicted in flow code, and the surface temperature and pyrolysis gas injection rate are computed in material response code. It is demonstrated that the time-lagged explicit approach is sufficient for simulations at low surface heating conditions, in which the surface ablation rate is not a strong function of the surface temperature. At elevated surface heating conditions, the implicit approach has to be taken, because the carbon ablation rate becomes a stiff function of the surface temperature, and thus the explicit approach appears to be inappropriate resulting in severe numerical oscillations of predicted surface temperature. Implicit coupling for simulation of arc-jet models is performed, and the predictions are compared with measured data. Implicit coupling for trajectory based simulation of Stardust fore-body heat shield is also conducted. The predicted stagnation point total recession is compared with that predicted using the chemical equilibrium surface assumption.

\section{Nomenclature}

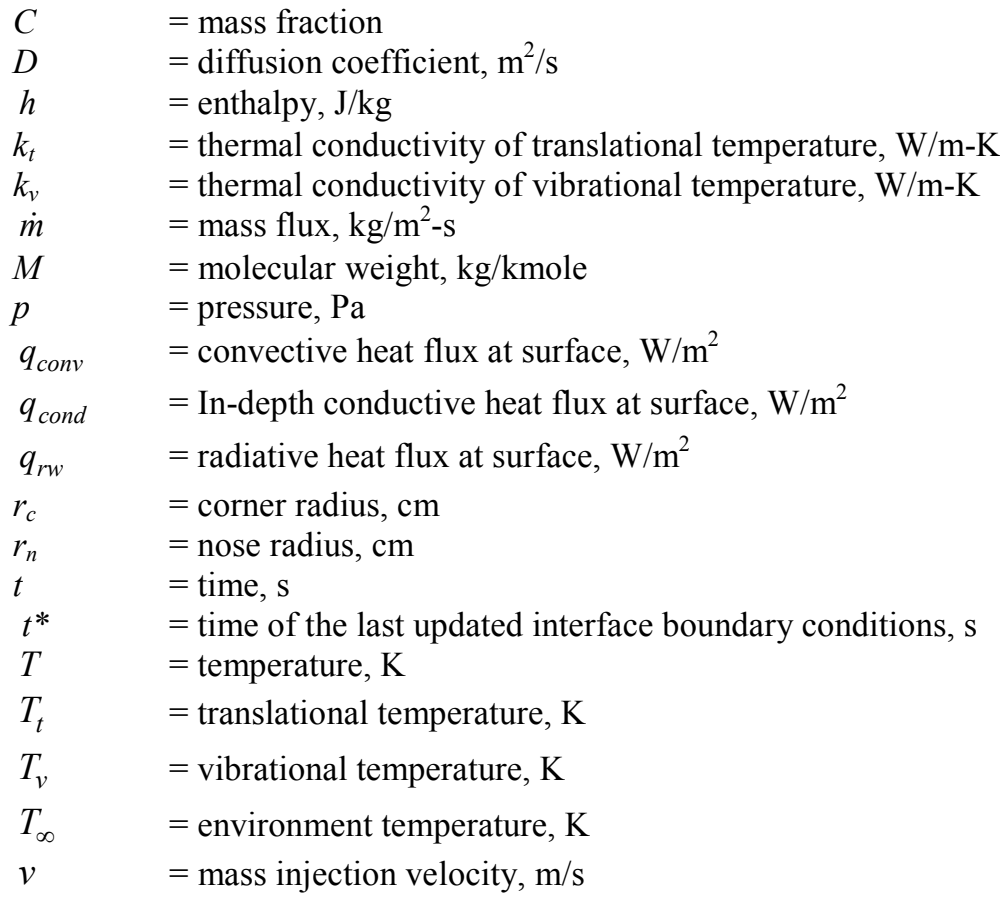

\footnotetext{
* Aerospace Engineer, Thermal Protection Materials Branch, MS 234-1, Senior Member AIAA.

${ }^{\dagger}$ Senior Research Scientist, Associate Fellow AIAA.
} 


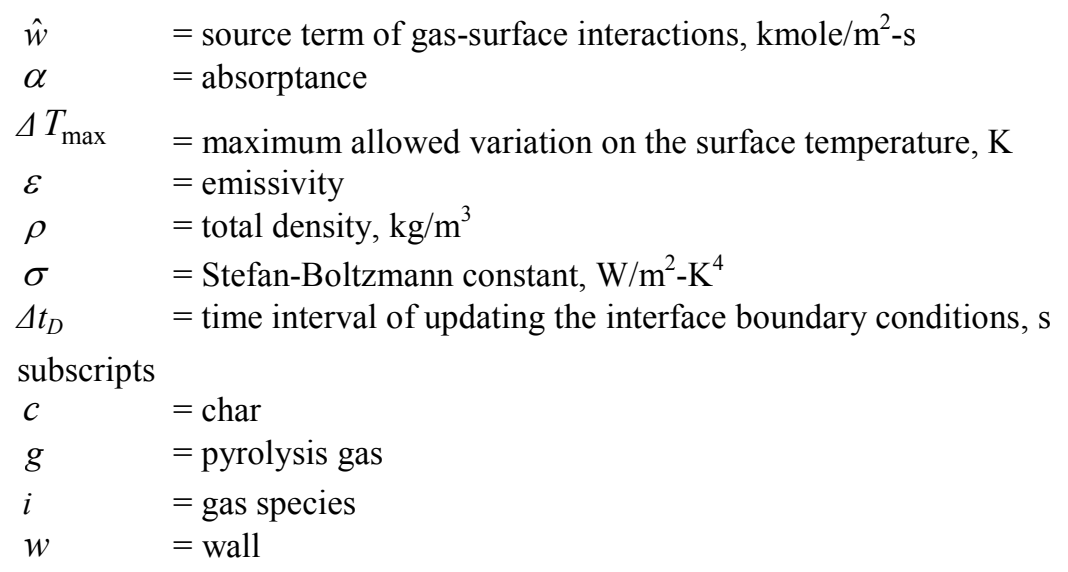

\section{Introduction}

Vehicles designed for Earth entry at super-orbital velocities, as well as those designed for ballistic entry at orbital velocities, typically use thermal protection system (TPS) materials that pyrolyze and ablate at high temperature for mass-efficient rejection of the aerothermal heat load. For design and sizing of ablating TPS materials, it is imperative to have reliable numerical procedures which can accurately compute the vehicle aerothermal environment, the material surface ablation, and the material internal thermal response. It has been demonstrated that accurate prediction of ablative heat flux also requires a fluid-solid shape change coupling simulation. ${ }^{1,2}$ In our previous fluid-solid shape change coupling computations, the ablative carbon surface was assumed to be at chemical equilibrium. Chemical equilibrium is a good assumption for many space entry applications, but it may not be valid for all conditions. Besides, the aerothermal environments computed by Data Parallel Line Relaxation method (DPLR) ${ }^{3}$ were those for a fully catalytic non-ablating surface. Thus, an engineering correlation with blowing reduction parameter had to be introduced in the Two-dimensional Implicit Thermalresponse and AblatioN program (TITAN) ${ }^{4}$ simulation to take into account the effect of mass injection on reduction of convective heat flux. A mass transfer coefficient also had to be defined based on the heat transfer coefficient under the assumption of a relatively thin boundary layer for the computation of char recession rate. In our recent study ${ }^{5}$, integrated fluid-material response analyses with finite rate gas-surface interactions were performed. The coupling procedure, considering surface thermal chemistry and shape change, was achieved using an explicit (time lagged) approach. This explicit approach was proved to be sufficient for shape change coupling simulations demonstrated in Refs. 1 and 2. However, for explicit coupling simulations with surface thermal chemistry included, numerical oscillation of predicted surface temperature was observed at conditions with relatively high surface heat fluxes. ${ }^{5}$ The time step size for updating the interface boundary conditions had to be reduced to minimize the numerical oscillation. Consequently, the total computational time required to complete a simulation increased significantly. Additionally, for some explicit coupling simulations, the numerical oscillation of surface temperature became so severe that a converged solution was not obtained. Thus, an alternative approach needs to be developed to efficiently perform fluid-solid surface thermal chemistry coupling at high surface heating environments.

The purpose of this paper is to demonstrate an implicit DPLR/3dFIAT coupling simulation system and its applications to the arc-jet simulation and the trajectory-based simulation of Stardust Earth Reentry Capsule. The boundary condition with general non-equilibrium finite-rate chemistry for gas/surface interactions implemented in the DPLR code by MacLean ${ }^{6}$ is used to predict char mass injection rate. In this simulation system, the surface species mass balance is performed in DPLR, and the surface energy balance is performed in 3dFIAT. The chemical equilibrium assumption typically used in material thermal response code can be removed. The hot-wall ablating convective heat flux is directly computed in DPLR based on the surface temperature and pyrolysis gas injection rate computed in 3dFIAT. The non-equilibrium gas/surface interaction chemistry between air and carbon surface is based on that developed by Park ${ }^{7}$ and is modified to better match the arc-jet data. Coupled fluid-material response analyses of stagnation tests conducted in NASA Ames Research Center arc-jet facilities are first performed for code validation. The ablating material used in these arc-jet tests is a Phenolic Impregnated Carbon Ablator (PICA). ${ }^{8}$ The predictions of using implicit coupling algorithm are compared with arc-jet data for seven selected CEV ADP arc-jet tests. Then, the implicit approach is used for trajectory-based simulation. A trajectory based simulation for Stardust 
Earth Reentry Capsule is computed successfully using the implicit approach. The predictions are presented and discussed in detail.

\section{Surface Thermal Chemistry and Shape Change Coupling}

The code coupling is basically the management of information exchange to satisfy all the conservation laws at the interfaces. Shape change coupling tracks the time-dependent moving interfaces, and thermochemistry coupling enforces the mass and energy balances at the interfaces. Shape change coupling also requires a moving volumetric grid system to reflect the corresponding moving interfaces. Thermochemistry coupling updates the boundary conditions on both sides of interface. If the boundary conditions are updated in a time-lagged manner, it is called an explicit approach. If the boundary conditions are updated as part of the solution, then it is called implicit approach. For the implicit approach in this paper, the interface boundary conditions are assumed to be piecewise linear in time, and additional iterations are performed to obtain the updated interface boundary conditions.

The interface boundary conditions between a TPS material and its surrounding flow field can be defined by solving species mass conservation and energy balance equations. Species mass conservation at the surface of TPS material is written as: ${ }^{9}$

$$
-\rho D_{i} \nabla C_{i}+\rho v_{w} C_{i}=M_{i} \hat{w}_{i}+\dot{m}_{g} C_{i, g}
$$

The first term on the left-hand side is mass transfer through diffusion, and the second term is mass transfer due to convection. On the right-hand side are the source terms due to gas-surface interaction and pyrolysis gas injection. Based on global mass balance at the surface, the following equation for the total mass blowing rate is expressed as:

$$
\rho v_{w}=\dot{m}_{c}+\dot{m}_{g}
$$

The total convective heat flux to the surface for the flow field that includes a two-temperature model is given as:

$$
q_{\text {conv }}=-k_{t} \nabla T_{t}-k_{v} \nabla T_{v}+\sum h_{i} \rho D_{i} \nabla C_{i} .
$$

Energy conservation equation at the surface of TPS material is written as

$$
q_{\text {conv }}+\dot{m}_{c}\left(h_{c}-h_{w}\right)+\dot{m}_{g}\left(h_{g}-h_{w}\right)+\alpha_{w} q_{r w}-\sigma \varepsilon_{w}\left(T_{w}^{4}-T_{\infty}^{4}\right)-q_{\text {cond }}=0
$$

The first term in Equation (4) is the total convective heat flux, the second and third terms represent the heat of ablation, the fourth and fifth terms are radiation absorption and emission, respectively, and the final term is the rate of heat conduction into the TPS material.

To obtain the solutions of Equations (1) to (4) requires the computations of thermal and species diffusion rates of flow field at the surface as well as thermal diffusion and pyrolysis gas injection rates of TPS material at the surface. The governing equations for both fluid and solid can be solved simultaneously along with Equations (1) through (4). However, for many simulations, flow solver and material response code are two independent programs, and a coupled simulation is usually applied. In a coupled simulation, the governing equations for fluid and solid are solved separately, and Equations (1) to (4) are solved either in the flow code or in the material thermal response code. Thus, communication between two codes needs to be established for exchanging information on surface thermal chemistry and shape change.

If the material surface is at chemical equilibrium, both the mass and energy conservation equations at the surface can be performed in the material simulation code as described in our previous work. ${ }^{1,2}$ For a chemical equilibrium surface, the chemical species at the surface are determined by using a chemical equilibrium code, such as $\mathrm{ACE}^{10}$ or MAT. ${ }^{11}$ In our chemical equilibrium analyses, the hot wall ablating heat flux was estimated from the cold wall nonablating heat flux using an engineering correlation with a blowing reduction parameter. Also, species mass transfer rate was assumed to be proportional to heat transfer rate based on a constant Lewis number. Under these assumptions, surface thermal chemistry coupling is not required, and only shape change information has to be exchanged between flow solver and material response code to correctly predict the aerothermal environments and material thermal response.

For a general finite-rate surface boundary condition, the approach taken here is solving the species mass conservation equation (Eq. 1) with the flow-field governing equations and solving the total energy balance equation 
(Eq. 4) with the solid material governing equations. If the information of surface thermochemistry and shape change shared between flow solver and material response solver is time lagged, it is an explicit approach. For explicit coupling approach, the interface boundary conditions for material response code are assumed to be piecewise constant in time. In other words, the boundary conditions during $\Delta t_{D}$ are equal to those at $t^{*}$. The time step to update the interface boundary conditions, $\Delta \mathrm{t}_{\mathrm{D}}$, can be varied dynamically. This time step may become unrealistically small due to numerical instabilities. For implicit coupling approach studied in this paper, the boundary conditions for material thermal response code are assumed to be piecewise linear in time. The boundary conditions during each $\Delta \mathrm{t}_{\mathrm{D}}$ are calculated by linear interpolation between $t^{*}$ and $t^{*}+\Delta t_{D}$. The interface boundary conditions at $t^{*}+\Delta t_{D}$ are unknown and thus have to be obtained through iterations. This approach is more computationally time intensive as compared with explicit coupling for completing each time cycle of $\Delta t_{D}$. However, the implicit approach can reduce the numerical oscillations, and may decrease the total run time. If the surface boundary condition is a stiff function of time or surface temperature, such as that for a sublimating carbon surface, the implicit approach is superior to explicit approach for conducting an integrated fluid-solid simulation. Either a constant time step or a variable time step can be used for updating the interface boundary conditions implicitly, as long as time accuracy is maintained.

The schematic diagram in Figure 1 depicts how the implicitly coupled simulation is performed. This is a time accurate simulation, and computations start from a time marching in the material response simulation code using the boundary conditions of cold-wall non-ablating convective heat flux and surface pressure estimated based on initial free stream conditions. Time integration is carried from $t=t^{*}$ to $t=t^{*}+\Delta t_{D}$. Since the boundary conditions at the end of integration are unknown, they have to be obtained through iterations. In the first iteration, the boundary conditions at $t=t^{*}+\Delta t_{D}$ is set to be equal to those at $t=t^{*}$. This is the initial guess of the interface boundary conditions at $t^{*}+\Delta t_{D}$. At the end of each time integration, if the maximum surface temperature variation at $t=t^{*+}$ $\Delta t_{D}$ exceeds the pre-determined value, the material thermal response computation is temporarily put in a waiting mode and flow field simulation is performed using the latest predicted surface temperature and pyrolysis gas injection. The pyrolysis gas is assumed to be at chemical equilibrium before being injected into the adjacent air. This assumption was proved to be reasonable for conditions studied in this paper. ${ }^{12}$ The computational grid system for the flow field is reconstructed based on the shape change predicted by the material response code. The free stream conditions are also updated according to the proposed flight trajectory. Each flow simulation is a steady-state computation. When the steady-state flow/radiation solution is obtained, the time-dependent material response simulation is resumed using the newly predicted surface heat flux, pressure, char mass injection rate, and surface radiation as the boundary conditions at the time step of $t^{*}+\Delta t_{D}$. It usually takes about 3 to 5 cycles of iterative loop to obtain the converged boundary conditions at $t^{*+} \Delta t_{D}$. If there is no iterations performed, this approach converts to the explicit coupling. Thus, the explicit approach is just a simplified version of the implicit approach. The explicit approach is similar to the implicit approach in which only one single cycle of iterative loop is performed during each time marching interval of $\Delta t_{D}$. This iterative process repeats for each $\Delta t_{D}$ until the end of flight trajectory or arc-jet exposure.

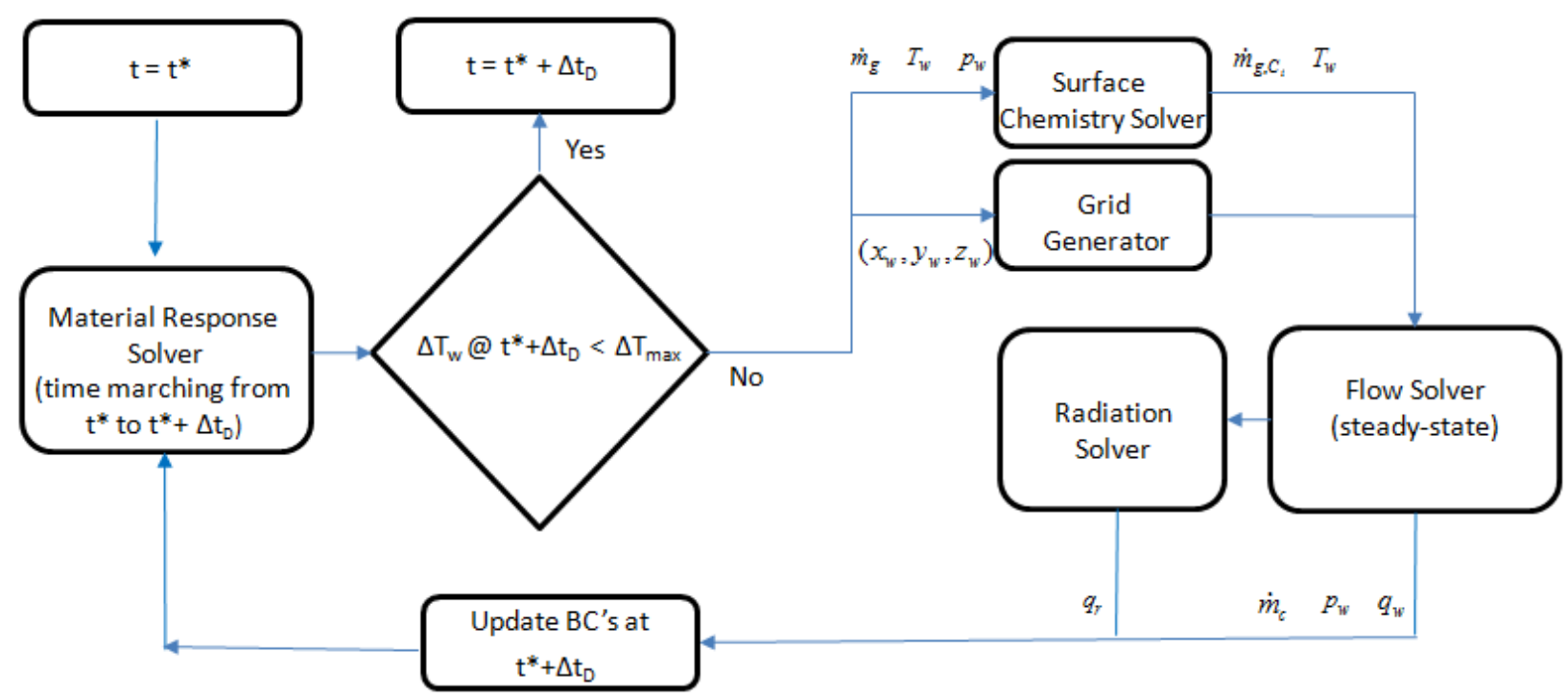


Figure 1 Flow chart for implicit surface thermal chemistry and shape change coupling.

\section{Chemistry Models}

Two sets of non-equilibrium gas/surface interaction models between air and a carbon surface were found in the open literature. The first set was developed by Park $^{7}$. In our previous study, the nitridation reaction in the original Park's model was replaced by the nitrogen recombination reaction to be consistent with observations in arc-jet tests using pure nitrogen gas. ${ }^{5}$ The second set was developed by Zhluktov et. at. ${ }^{13}$ However, it was found in our previous work ${ }^{5}$ that Zhluktov's model far under-predicted PICA recession. Thus, Zhluktov's model is not considered in this work, and Park's carbon sublimation model is revised to better match the arc-jet data. The modified Park's gas/surface reactions used in this paper are listed below:

$$
\begin{aligned}
& \text { Modified Park Carbon/Air Chemistry: } \\
& \begin{array}{ll}
\text { \#1 } & \mathrm{O}+\mathrm{C}(\mathrm{b}) \rightarrow \mathrm{CO} \\
\# \mathrm{P} 2 & \mathrm{O}_{2}+2 \mathrm{C}(\mathrm{b}) \rightarrow 2 \mathrm{CO} \\
\# \mathrm{P} 3 & 2 \mathrm{~N} \rightarrow \mathrm{N}_{2} \\
\# \mathrm{P} 4 & 3 \mathrm{C}(\mathrm{b}) \rightarrow \mathrm{C}_{3} \\
\# \mathrm{P} 5 & \mathrm{C}_{3} \rightarrow 3 \mathrm{C}(\mathrm{b})
\end{array}
\end{aligned}
$$

Here $\mathrm{C}(\mathrm{b})$ represents the solid carbon species. In reaction \#P3, nitrogen atoms are assumed to be fully recombined at the surface. To better agree with arc-jet data in the sublimation region, the pre-exponential factors of reaction rate constants for reactions \#P4 and \#P5 used in this work are $8.27 \times 10^{14}$ and 0.25 . The rest of rate constants can be found in Refs 6 and 9. Marschall developed a general formulation for finite-rate gas and surface interactions. ${ }^{14}$ The DPLR code was enhanced by MacLean based on Marschall's work to solve the surface species mass balance equation for the finite-rate gas surface reactions. The detail of his implementation can be found in Ref. 6. All flow simulations presented in this work are performed using this version of DPLR code (DPLR/4.03.0cvs).

There are twenty nine gas phase chemical species used in this study for the simulation of PICA and airArgon interactions. The chemical species are $\mathrm{CO}_{2}, \mathrm{CO}, \mathrm{N}_{2}, \mathrm{O}_{2}, \mathrm{NO}, \mathrm{C}_{2}, \mathrm{C}_{3}, \mathrm{CN}, \mathrm{H}_{2}, \mathrm{HCN}, \mathrm{C}, \mathrm{N}, \mathrm{O}, \mathrm{H}, \mathrm{CH}, \mathrm{CH}_{2}$, $\mathrm{C}_{2} \mathrm{H}, \mathrm{C}_{2} \mathrm{H}_{2}, \mathrm{C}_{4}, \mathrm{C}_{3} \mathrm{H}, \mathrm{C}_{4} \mathrm{H}, \mathrm{Ar}, \mathrm{N}^{+} \mathrm{O}_{2}^{+} \mathrm{NO}^{+} \mathrm{C}^{+} \mathrm{N}^{+} \mathrm{O}^{+}$and $\mathrm{e}^{-}$. These species were selected based on a chemical equilibrium computation for a PICA/air-Argon system. Their enthalpy makes up more than $95 \%$ of total gas enthalpy compared with the baseline 119 chemical equilibrium species model developed by Orion TPS Advanced Development Project. ${ }^{15}$ The gas phase chemical reactions considered in the simulations are as follows.

$$
\begin{array}{ll}
\# 1 & \mathrm{CO}_{2}+\mathrm{M} \leftrightarrow \mathrm{CO}+\mathrm{O}+\mathrm{M} \\
\# 2 & \mathrm{CO}+\mathrm{M} \leftrightarrow \mathrm{C}+\mathrm{O}+\mathrm{M} \\
\# 3 & \mathrm{~N}_{2}+\mathrm{M} \leftrightarrow \mathrm{N}+\mathrm{N}+\mathrm{M} \\
\# 4 & \mathrm{O}_{2}+\mathrm{M} \leftrightarrow \mathrm{O}+\mathrm{O}+\mathrm{M} \\
\# 5 & \mathrm{NO}+\mathrm{M} \leftrightarrow \mathrm{N}+\mathrm{O}+\mathrm{M} \\
\# 6 & \mathrm{C}_{2}+\mathrm{M} \leftrightarrow \mathrm{C}+\mathrm{C}+\mathrm{M} \\
\# 7 & \mathrm{C}_{3}+\mathrm{M} \leftrightarrow \mathrm{C}_{2}+\mathrm{C}+\mathrm{M} \\
\# 8 & \mathrm{CN}+\mathrm{M} \leftrightarrow \mathrm{C}+\mathrm{N}+\mathrm{M} \\
\# 9 & \mathrm{H}_{2}+\mathrm{M} \leftrightarrow \mathrm{H}+\mathrm{H}+\mathrm{M} \\
\# 10 & \mathrm{~N}_{2}+\mathrm{Ar} \leftrightarrow \mathrm{N}+\mathrm{N}+\mathrm{Ar} \\
\# 11 & \mathrm{O}_{2}+\mathrm{Ar} \leftrightarrow \mathrm{O}+\mathrm{O}+\mathrm{Ar} \\
\# 12 & \mathrm{NO}+\mathrm{Ar} \leftrightarrow \mathrm{N}+\mathrm{O}+\mathrm{Ar} \\
\# 13 & \mathrm{NO}+\mathrm{O} \leftrightarrow \mathrm{O}_{2}+\mathrm{N} \\
\# 14 & \mathrm{~N}_{2}+\mathrm{O} \leftrightarrow \mathrm{NO}+\mathrm{N} \\
\# 15 & \mathrm{CO}+\mathrm{O} \leftrightarrow \mathrm{O}_{2}+\mathrm{C} \\
\# 16 & \mathrm{CO}+\mathrm{O} \leftrightarrow \mathrm{O}_{2}+\mathrm{CO} \\
\# 17 & \mathrm{CO}+\mathrm{C} \leftrightarrow \mathrm{C}_{2}+\mathrm{O} \\
\# 18 & \mathrm{CO}+\mathrm{N} \leftrightarrow \mathrm{CN}+\mathrm{O} \\
\# 19 & \mathrm{~N}_{2}+\mathrm{C} \leftrightarrow \mathrm{CN}+\mathrm{N}
\end{array}
$$




$$
\begin{aligned}
& \# 20 \mathrm{CN}+\mathrm{O} \leftrightarrow \mathrm{NO}+\mathrm{C} \\
& \# 21 \mathrm{CN}+\mathrm{C} \leftrightarrow \mathrm{C}_{2}+\mathrm{N} \\
& \text { \#22 } \mathrm{HCN}+\mathrm{H} \leftrightarrow \mathrm{CN}+\mathrm{H}_{2} \\
& \text { \#23 } \mathrm{CH}+\mathrm{M} \leftrightarrow \mathrm{C}+\mathrm{H}+\mathrm{M} \\
& \text { \#24 } \mathrm{CH}_{2}+\mathrm{M} \leftrightarrow \mathrm{C}+\mathrm{H}_{2}+\mathrm{M} \\
& \text { \#25 } \mathrm{CH}_{2}+\mathrm{M} \leftrightarrow \mathrm{CH}+\mathrm{H}+\mathrm{M} \\
& \text { \#26 } \mathrm{C}_{2} \mathrm{H}+\mathrm{M} \leftrightarrow \mathrm{C}_{2}+\mathrm{H}+\mathrm{M} \\
& \text { \#27 } \mathrm{C}_{2} \mathrm{H}_{2}+\mathrm{M} \leftrightarrow \mathrm{C}_{2} \mathrm{H}+\mathrm{H}+\mathrm{M} \\
& \# 28 \quad \mathrm{C}_{2}+\mathrm{C}_{2} \leftrightarrow \mathrm{C}_{3}+\mathrm{C} \\
& \text { \#29 } \mathrm{C}_{2}+\mathrm{H}_{2} \leftrightarrow \mathrm{C}_{2} \mathrm{H}+\mathrm{H} \\
& \text { \#30 } \quad \mathrm{CH}_{2}+\mathrm{C} \leftrightarrow \mathrm{CH}+\mathrm{CH} \\
& \text { \#31 } \mathrm{CH}_{2}+\mathrm{CH}_{2} \leftrightarrow \mathrm{C}_{2} \mathrm{H}_{2}+\mathrm{H}_{2} \\
& \text { \#32 } \mathrm{CH}_{2}+\mathrm{C} \leftrightarrow \mathrm{C}_{2} \mathrm{H}+\mathrm{H} \\
& \text { \#33 } \mathrm{CH}_{2}+\mathrm{C}_{2} \mathrm{H} \leftrightarrow \mathrm{CH}+\mathrm{C}_{2} \mathrm{H}_{2} \\
& \text { \#34 } \mathrm{CH}+\mathrm{CH} \leftrightarrow \mathrm{C}_{2} \mathrm{H}+\mathrm{H} \\
& \text { \#35 } \mathrm{CH}+\mathrm{C}_{2} \mathrm{H} \leftrightarrow \mathrm{C}_{2} \mathrm{H}_{2}+\mathrm{C} \\
& \text { \#36 } \mathrm{CH}_{2}+\mathrm{CH}_{2} \leftrightarrow \mathrm{C}_{2} \mathrm{H}_{2}+\mathrm{H}+\mathrm{H} \\
& \text { \#37 } \mathrm{C}_{2}+\mathrm{C}_{2}+\mathrm{M} \leftrightarrow \mathrm{C}_{4}+\mathrm{M} \\
& \text { \#38 } \mathrm{C}+\mathrm{CH} \leftrightarrow \mathrm{C}_{2}+\mathrm{H} \\
& \text { \#39 } \mathrm{C}+\mathrm{C}_{2} \mathrm{H} \leftrightarrow \mathrm{C}_{3}+\mathrm{H} \\
& \# 40 \quad \mathrm{C}_{2}+\mathrm{CH} \leftrightarrow \mathrm{C}_{3}+\mathrm{H} \\
& \# 41 \mathrm{C}_{2}+\mathrm{C}_{2} \mathrm{H} \leftrightarrow \mathrm{C}_{4}+\mathrm{H} \\
& \text { \#42 } \mathrm{CH}+\mathrm{H} \leftrightarrow \mathrm{C}+\mathrm{H}_{2} \\
& \text { \#43 } \mathrm{CH}_{2}+\mathrm{H} \leftrightarrow \mathrm{CH}+\mathrm{H}_{2} \\
& \text { \#44 } \mathrm{C}_{2} \mathrm{H}+\mathrm{C}_{2} \mathrm{H} \leftrightarrow \mathrm{C}_{2} \mathrm{H}_{2}+\mathrm{C}_{2} \\
& \text { \#45 } \mathrm{C}+\mathrm{C}_{2} \mathrm{H}_{2} \leftrightarrow \mathrm{C}_{3} \mathrm{H}+\mathrm{H} \\
& \text { \#46 } \mathrm{C}_{2}+\mathrm{C}_{2} \mathrm{H}_{2} \leftrightarrow \mathrm{C}_{4} \mathrm{H}+\mathrm{H} \\
& \# 47 \quad \mathrm{C}_{2}+\mathrm{C}_{4} \mathrm{H} \leftrightarrow \mathrm{C}_{2} \mathrm{H}+\mathrm{C}_{4} \\
& \text { \#48 } \mathrm{C}_{2} \mathrm{H}+\mathrm{C}_{2} \mathrm{H} \leftrightarrow \mathrm{C}_{4} \mathrm{H}+\mathrm{H} \\
& \# 49 \quad \mathrm{C}_{3} \mathrm{H}+\mathrm{H} \leftrightarrow \mathrm{C}_{3}+\mathrm{H}_{2} \\
& \# 50 \quad \mathrm{C}_{4} \mathrm{H}+\mathrm{H} \leftrightarrow \mathrm{C}_{4}+\mathrm{H}_{2} \\
& \# 51 \mathrm{H}+\mathrm{C}_{4}+\mathrm{M} \leftrightarrow \mathrm{C}_{4} \mathrm{H}+\mathrm{M} \\
& \# 52 \mathrm{CH}+\mathrm{CH} \leftrightarrow \mathrm{C}_{2}+\mathrm{H}+\mathrm{H} \\
& \text { \#53 } \quad \mathrm{C}_{2} \mathrm{H}+\mathrm{H}_{2} \leftrightarrow \mathrm{C}_{2} \mathrm{H}_{2}+\mathrm{H} \\
& \text { \#54 } \mathrm{C}+\mathrm{e}^{-} \leftrightarrow \mathrm{C}^{+}+\mathrm{e}^{-}+\mathrm{e}^{-} \\
& \text {\#55 } \mathrm{N}+\mathrm{e}^{-} \leftrightarrow \mathrm{N}^{+}+\mathrm{e}^{-}+\mathrm{e}^{-} \\
& \text {\#56 } \mathrm{O}+\mathrm{e}^{-} \leftrightarrow \mathrm{O}^{+}+\mathrm{e}^{-}+\mathrm{e}^{-} \\
& \text {\#57 } \mathrm{N}+\mathrm{O} \leftrightarrow \mathrm{NO}^{+}+\mathrm{e}^{-} \\
& \text {\#58 } \mathrm{N}+\mathrm{N} \leftrightarrow \mathrm{N}_{2}^{+}+\mathrm{e}^{-} \\
& \text {\#59 } \mathrm{O}+\mathrm{O} \leftrightarrow \mathrm{O}_{2}^{+}+\mathrm{e}^{-} \\
& \# 60 \mathrm{~N}^{+}+\mathrm{N}_{2} \leftrightarrow \mathrm{N}_{2}^{+}+\mathrm{N} \\
& \# 61 \mathrm{O}^{+}+\mathrm{N}_{2} \leftrightarrow \mathrm{N}_{2}^{+}+\mathrm{O} \\
& \text { \#62 } \mathrm{O}_{2}^{+}+\mathrm{O} \leftrightarrow \mathrm{O}^{+}+\mathrm{O}_{2} \\
& \text { \#63 } \mathrm{O}^{+}+\mathrm{NO} \leftrightarrow \mathrm{N}^{+}+\mathrm{O}_{2} \\
& \text { \#64 } \mathrm{NO}^{+}+\mathrm{O}_{2} \leftrightarrow \mathrm{O}_{2}^{+}+\mathrm{NO} \\
& \# 65 \mathrm{NO}^{+}+\mathrm{N} \leftrightarrow \mathrm{N}_{2}^{+}+\mathrm{O} \\
& \text { \#66 } \mathrm{NO}^{+}+\mathrm{O} \leftrightarrow \mathrm{N}^{+}+\mathrm{O}_{2} \\
& \text { \#67 } \mathrm{O}_{2}^{+}+\mathrm{N} \leftrightarrow \mathrm{N}^{+}+\mathrm{O}_{2} \\
& \text { \#68 } \mathrm{O}_{2}^{+}+\mathrm{N}_{2} \leftrightarrow \mathrm{N}_{2}^{+}+\mathrm{O}_{2} \\
& \text { \#69 } \mathrm{NO}^{+}+\mathrm{N} \leftrightarrow \mathrm{O}^{+}+\mathrm{N}_{2} \\
& \# 70 \mathrm{NO}^{+}+\mathrm{O} \leftrightarrow \mathrm{O}_{2}^{+}+\mathrm{N}
\end{aligned}
$$

The reaction rates for reactions \#1-22 are taken from the work of Olynick et al. ${ }^{16}$ for Stardust earth entry simulations. The rates for reactions \#23-36 are taken from Gökçen's ${ }^{17}$ paper for simulations of Titan atmosphere 
entry. The rates for reactions \#37-53 are taken from the study of Kruse et al. ${ }^{18}$ for high-temperature pyrolysis of Acetylene. The rates for reactions \#54-70 are taken from Park et al. ${ }^{19}$ for Mars entries.

\section{Results}

In this section, we present two sets of computation performed using the DPLR/3dFIAT coupled simulation system discussed in the previous sections. In the first set of computation, arc-jet simulations are performed. This is to demonstrate that the implementation of implicit coupling technique is self consistent and the time accurate solutions can be achieved. Predictions are compared with those predicted using the explicit approach, and with the data from seven selected Crew Exploration Vehicle Advanced Development Program (CEV ADP) arc-jet tests. In the second set of computations, trajectory-based simulations are performed for Stardust fore-body heat-shield during Earth reentry. Attempt has been made using the explicit approach to perform the same trajectory based simulation, but computation failed to converge around the peak heating point due to excessive numerical oscillation in predicted surface temperature.

\section{A. Arc-Jet Simulation}

Coupled DPLR/3dFIAT computations using the revised Park's finite-rate air-carbon gas/surface interaction model described early in this paper are performed for arc-jet flow over a stagnation test model. Model validation is accomplished by comparing the predictions with the data from seven selected CEV ADP arc-jet tests conducted over a range of stagnation heat flux and pressures ranging from $107 \mathrm{~W} / \mathrm{cm}^{2}$ at $2.3 \mathrm{kPa}$ to $1100 \mathrm{~W} / \mathrm{cm}^{2}$ at $84 \mathrm{kPa}{ }^{20} \mathrm{The}$ test conditions for these seven test cases are listed in Table 1.

Table 1: Seven arc-jet cases selected for detailed analysis.

\begin{tabular}{lllll}
\hline \hline Case number & $\begin{array}{l}\text { Stagnation point heat flux, } \\
\mathrm{W} / \mathrm{cm}^{2} \text { (cold wall) }\end{array}$ & $\begin{array}{l}\text { Stagnation point pressure, } \\
\mathrm{kPa}\end{array}$ & $\begin{array}{l}\text { Exposure time, } \\
\mathrm{s}\end{array}$ & $\begin{array}{l}\text { Total enthalpy } \\
\mathrm{MJ} / \mathrm{kg}\end{array}$ \\
\hline 1 & 107 & 2.3 & 55 & 15.2 \\
2 & 169 & 5.0 & 60 & 17.0 \\
3 & 246 & 8.5 & 42 & 19.3 \\
4 & 395 & 17.2 & 34 & 21.4 \\
5 & 552 & 27.3 & 30 & 23.3 \\
6 & 694 & 31.0 & 27 & 29.2 \\
7 & 1102 & 84.4 & 10 & 25.6 \\
\hline \hline
\end{tabular}

Figure 2 shows the geometry and material map of stagnation model used in these tests. The model nose radius is equal to the model diameter $\left(r_{n}=r_{D}=5.08 \mathrm{~cm}\right.$, and $\left.r_{c} / r_{n}=1 / 16\right)$, and the sides are cylindrical. This is the so called "iso-q" geometry. The tested TPS material is PICA. The detailed comparisons between two finite-rate air-carbon gas/surface interaction models (Park's and Zhulktov's) using a time lagged (explicit) coupling were discussed in our previous paper. ${ }^{5}$ In this study, the simulations for the same seven arc-jet cases are performed using the implicit approach. The PICA material in-depth thermal response and flow field structure predicted using implicit coupling are not presented in this paper, because they are essentially the same as those predicted using the explicit approach, and were discussed extensively in our previous paper. ${ }^{2}$ Here, we focus on the issue of numerical oscillation associated with fluid/solid coupled simulations, and the advantage/disadvantages of applying the implicit coupling to update the interface boundary conditions. Three of these seven arc-jet cases will be discussed in detail to explore the difference between the predictions using implicit and explicit approaches. Case 2 represents the low end side of heat flux $\left(169 \mathrm{~W} / \mathrm{cm}^{2}\right)$, while Cases 6 and 7 represent those at the high end side $\left(694\right.$ and $\left.1102 \mathrm{~W} / \mathrm{cm}^{2}\right)$. 


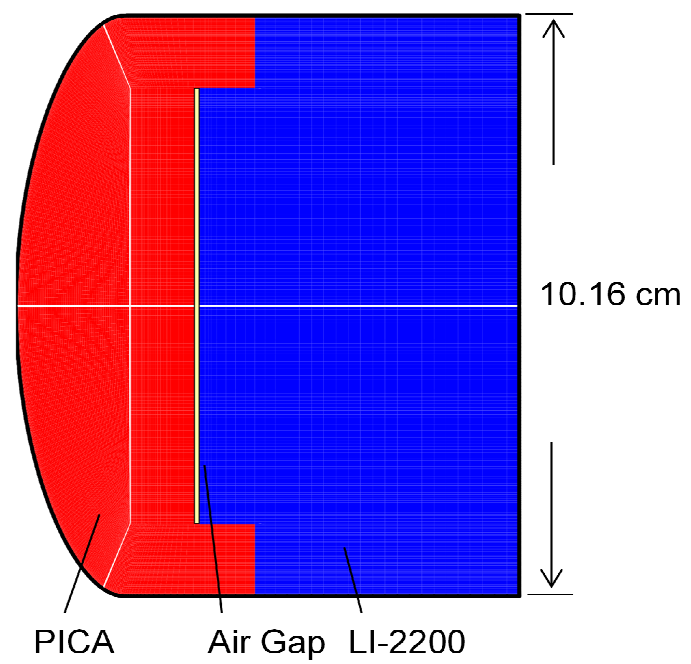

Figure 2 Geometry and material map of the model used in the arc-jet tests.

Figure 3a presents the predicted stagnation point temperature history for Case 2 during the first 5 seconds of simulations using both implicit (black line) and explicit (red line) coupling approach. Based on our experience, numerical oscillations in the surface temperature and mass injection rate normally occur during the first few seconds of arc-jet exposure because of the abrupt change to the surface environment. Thus, the comparison between these two predictions after the first 5 seconds is not presented. Since the surface heat flux is relatively benign for this case, the maximum stagnation point temperature is around $2200 \mathrm{~K}$. The difference on predicted surface temperature between two coupling approaches is small enough to be ignored. Figure $3 \mathrm{~b}$ shows the comparison of stagnation point mass injection rates of char and pyrolysis gas. The pyrolysis gas mass injection rate is higher than the char mass injection rate during the first 5 seconds. Aside from a few minor oscillations in the first few time steps of explicit simulation, the agreement is considered to be very good between these two approaches. In the implicit simulation, a fixed time step, $\Delta \mathrm{t}_{\mathrm{D}}$, of $0.1 \mathrm{~s}$ is used. This is the time step for DPLR and 3dFIAT to exchange interface information, not the time marching step in 3dFIAT. For the explicit approach, a variable time step is adopted to minimize the total computational time. In the first few time steps, the step size is of the order of $10^{-2} \mathrm{~s}$, and then gradually it increases up to about $0.25 \mathrm{~s}$. The time step size used in these two coupling simulations are quite different, but the predicted interface conditions, including temperature and mass injection rate, are almost identical. Since the numerical oscillations associated with the explicit coupling is insignificant under this surface heating condition, the explicit coupling with variable time step size appears to be more time efficient. The computational time for each implicit time step is equivalent to 3 to 5 explicit time steps, due to additional iterations. Unless the time step for the implicit simulation is 3 to 5 times greater than that of the explicit simulation and the time accuracy can still be maintained, the explicit coupling should be adequate. Thus there is no advantage of applying the implicit coupling for this case.

Similar comparison for Case 6 is shown in Figs 4 . Case 6 has stagnation point heat flux of $694 \mathrm{~W} / \mathrm{cm}^{2}$, which is much higher than that of Case 2. Figure 4a is the comparison of stagnation point temperature history and Fig. 4b presents stagnation point mass injection rate history during the first 5 seconds of arc-jet exposure. The maximum surface temperature reaches around $3100 \mathrm{~K}$. The variable time step is adopted in both computations. Numerical oscillations are observed in the results predicted by both approaches. The predictions using implicit approach (black lines) have much less variation in amplitude than those using explicit approach (red lines). Regardless of numerical oscillations, the agreement on predicted interface boundary conditions between these two approaches is reasonably good. During the first second of computation, the time step size used in the explicit coupling (order of $10^{-3} \mathrm{~s}$ ) is far smaller than that of the implicit coupling (order of $10^{-2} \mathrm{~s}$ ), but numerical oscillations still cannot be further reduced. The predictions after the first 5 seconds have no numerical oscillation and thus are not shown in Figs. 4. To further reduce numerical oscillations in the predictions using the explicit approach is impractical. Since the required time 
step size becomes unreasonably small. The implicit approach thus is a better choice for simulations for cases similar to that of Case 6 . The total run time of Case 6 for the implicit coupling is about $25 \%$ of that of the explicit coupling. The similar comparisons between the implicit and explicit approaches for Case 7 are shown in Fig. 5. The time step used for the explicit coupling is about one order of magnitude less than that of Case 6, while that for the implicit coupling remains the same as Case 6. The numerical oscillations are similar to those observed in Case 6. For conditions with even higher heat fluxes, the explicit coupling usually fails to converge because of excessive numerical oscillations even if the selected variable time step size is further reduced. The implicit approach thus becomes the more practical way to perform simulations at such conditions. Generally speaking, the agreement on predicted interface boundary conditions between implicit and explicit simulations is good as long as the numerical oscillation is moderate. The implicit approach has no instability issues but may have minor numerical oscillations, which mostly can be minimized by controlling the time step size. A fixed constant time step can be used in the implicit simulations for most applications. A variable time step is only used to minimize the numerical oscillations. The explicit approach requires less computational time to complete one single time step for updating the interface conditions, and its coding is fairly straightforward as compared with the implicit approach. The best application for the explicit approach is the fluid-solid chemical equilibrium shape change coupling, in which surface temperature and surface thermal chemistry are not involved in the coupling process.

The predicted stagnation point total recession values for all seven arc-jet cases are presented in Fig. 6, and are compared with the measurements. As mentioned in the previous section, the pre-exponential factors used in our surface sublimation reactions, \#P4 and \#P5, are different from those suggested by Park. The pre-exponential factors suggested by Park under-predicted the carbon sublimation by about $20 \%{ }^{5}$ The maximum difference between the computed and measured recession values for all seven cases is less than $5 \%$. The comparison of predicted stagnation point ablating hot-wall heat flux for the non-equilibrium and equilibrium surface chemistry model is shown in Fig. 7. The non-equilibrium model is the current finite-rate gas/surface interaction model, where as the chemical equilibrium model is our base-lined model with blowing reduction parameter of 0.5 . The predictions using the chemical equilibrium surface assumption are just slightly lower than those using the finite-rate model for all seven cases. Thus, this indicates that the chemical equilibrium surface is a reasonable approximation for prediction of stagnation point heat flux and surface recession under arc stream conditions studied in this section. 


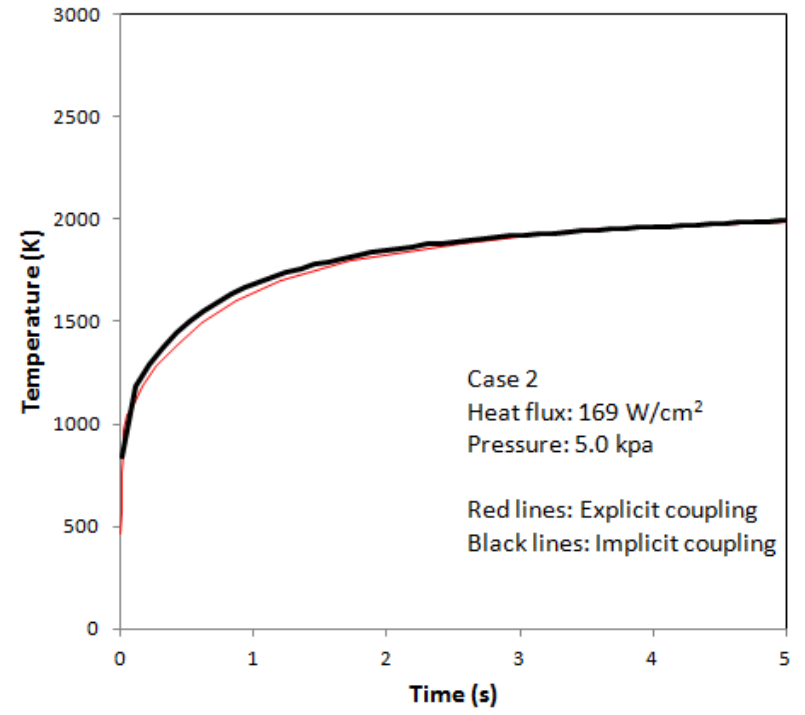

a) Surface temperature

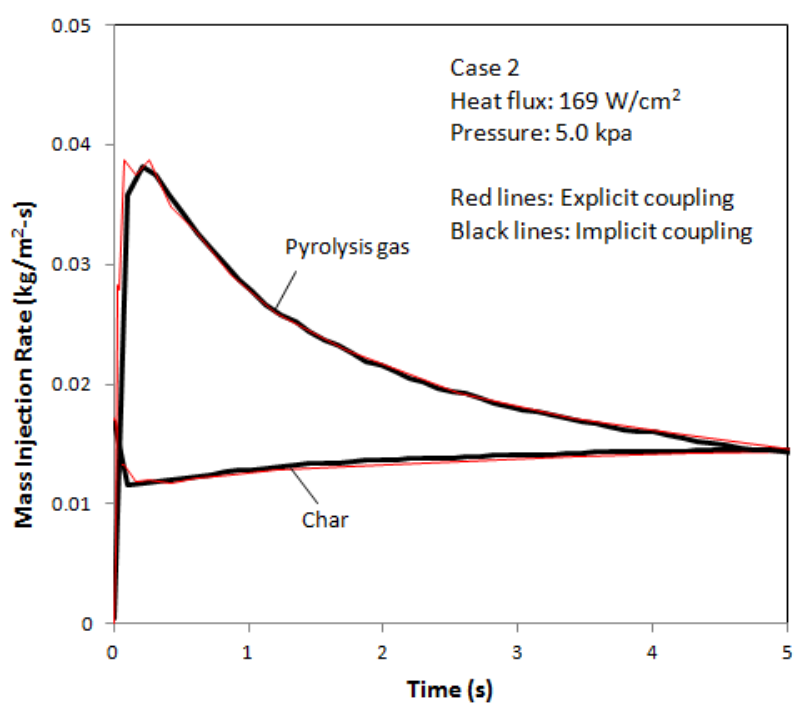

b) Mass injection rate (char and pyrolysis gas)

Figure 3 Comparison of stagnation-point time histories of various surface quantities for Case 2 using the implicit and explicit coupling approaches.

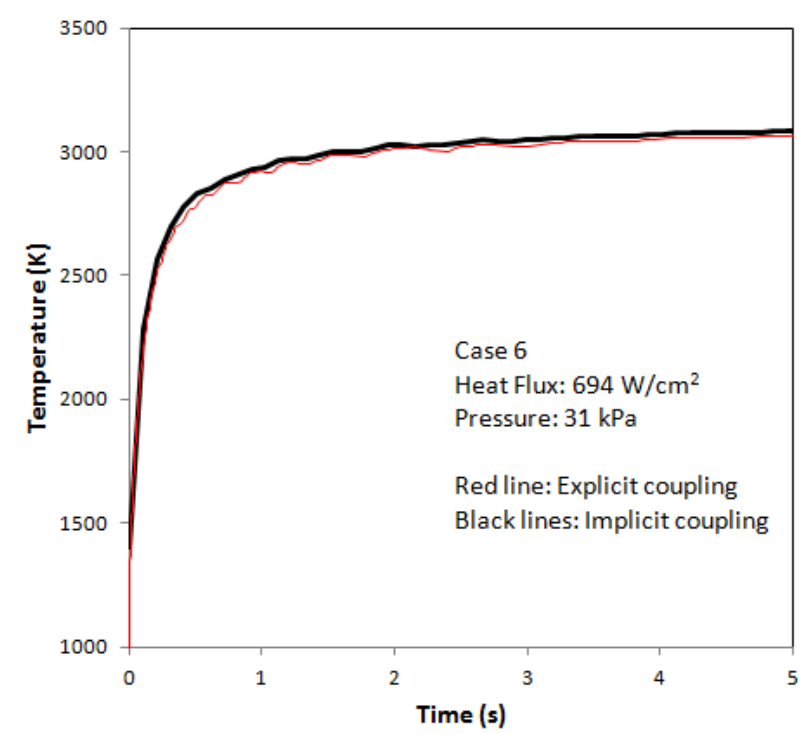

a) Surface temperature

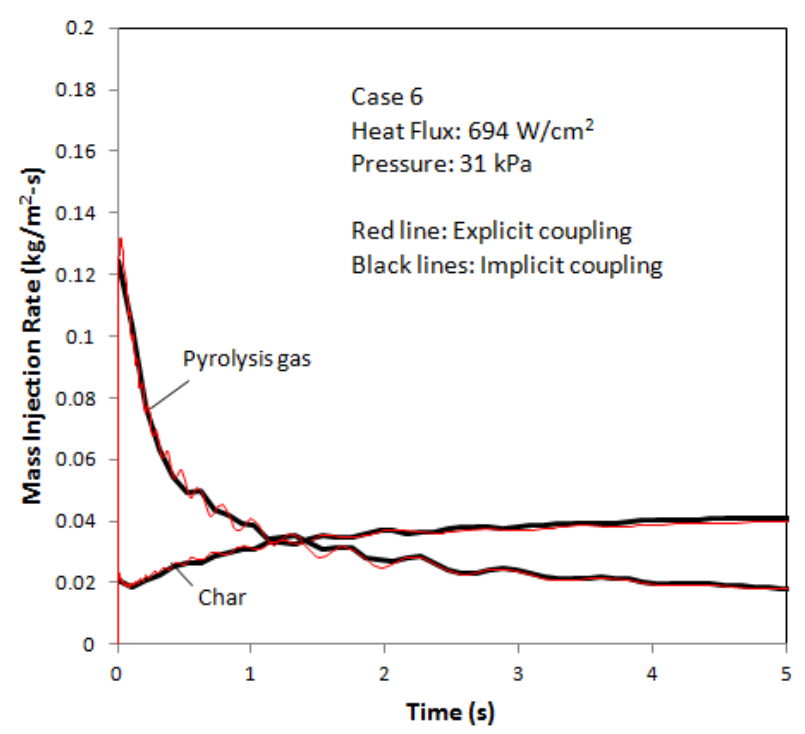

b) Mass injection rate (char and pyrolysis gas)

Figure 4 Comparison of stagnation-point time histories of various surface quantities for Case 6 using the implicit and explicit coupling approaches. 


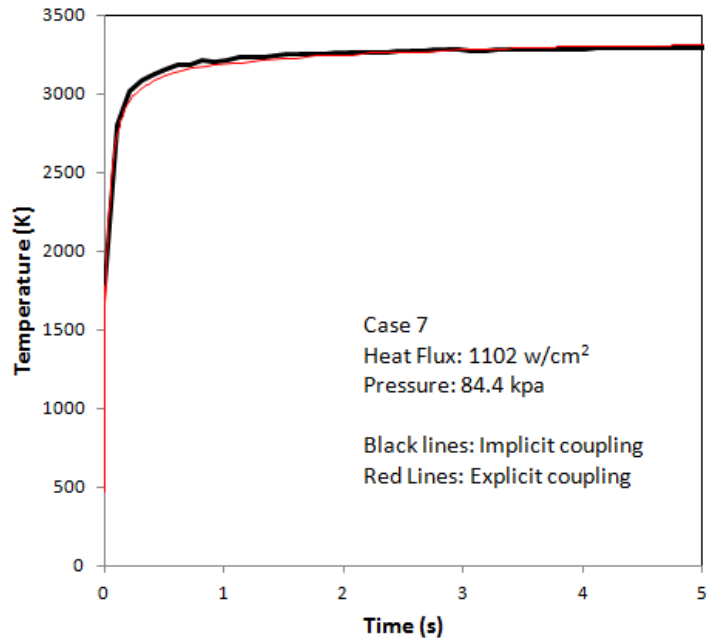

a) Surface temperature

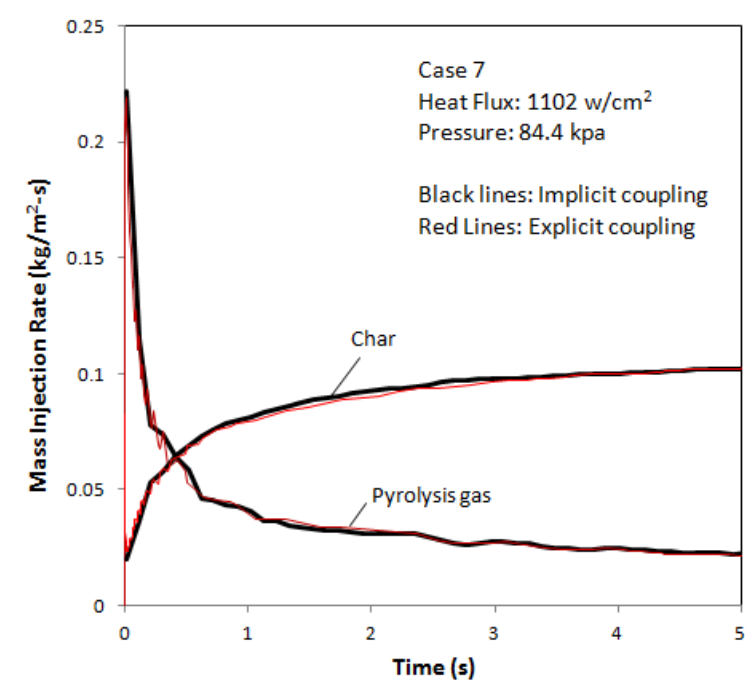

b) Mass injection rate (char and pyrolysis gas)

Figure 5 Comparison of stagnation-point time histories of various surface quantities for Case 7 using the implicit and explicit coupling approaches.

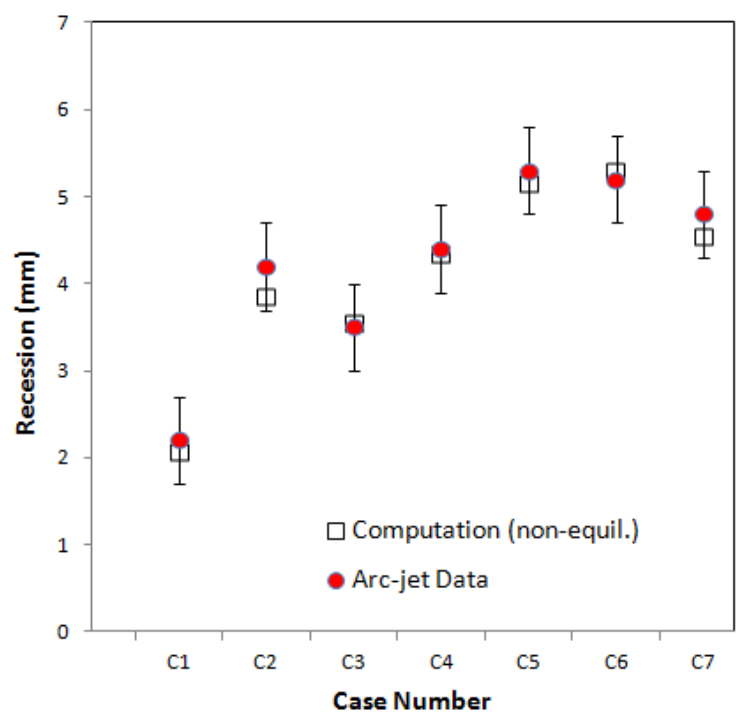

Figure 6 Comparison of the computed stagnation-point total recession with the arc-jet data.

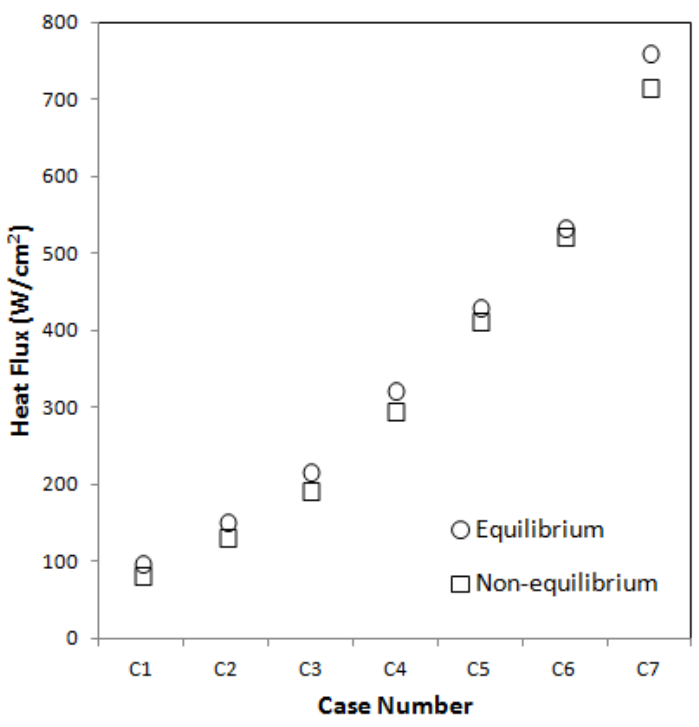

Figure 7 Comparison of the computed stagnation-point hot-wall heat fluxes for the chemical non-equilibrium and equilibrium models. 


\section{B. Trajectory Based Simulation - Stardust Earth Reentry Capsule}

The predictions of trajectory based simulation using implicit coupling between DPLR and 3dFIAT for Stardust fore-body heat-shield is presented in this section. The Stardust fore-body heat-shield material is PICA. The PICA surface was expected to reach the low sublimation region around the peak convective heating point. Thus, this is an ideal case to demonstrate the implicit coupling approach. The surface geometry for Stardust fore-body heat shield is an axi-symmetric 60-degree half angle sphere-cone with a nose radius of approximately $23 \mathrm{~cm}$. The size of computational grids for flow field calculation is $81 \times 91$, and that of material thermal response simulation is $81 \times 61$. The finite-rate gas phase chemistry and gas/surface interactions used in this simulation are the same as those used in the arc-jet simulation discussed in the previous section. In arc-jet simulation, the arc stream conditions are fixed in time, and the radiation emitted from the arc stream is negligibly small. For the trajectory-based simulation discussed in this section, the NEQAIR2009 code is used to estimate the radiation emitted from shock layer to the surface. ${ }^{21}$ The trajectory used in this simulation is shown in Fig. $8 .^{22}$ An attempt has been made using the explicit approach to perform this simulation. However, because of sever numerical oscillations starting at around $t=50 \mathrm{~s}$, no converged solution was obtained. Thus, comparison of predictions using the implicit and explicit coupling approaches is not available.

Similar trajectory based simulation was performed in Ref. 16, in which the gas/surface coupling simulation was conducted at 11 pre-selected trajectory points from 34 to $80 \mathrm{~s}$. Chemical equilibrium assumption was made at the heat-shield surface, and the effect of shape change was neglected. Additionally, the one-dimensional FIAT ${ }^{23}$ code was used for material ablation and thermal response simulation, and the NOVAR code was used to predict shock layer radiation in the work of Olynick et al. ${ }^{24}$

Before $t=35 \mathrm{~s}$, the solutions of full Navier-Stokes equations are not computed, due to low density effect. The continuous flow assumption may be in question. After $100 \mathrm{~s}$, the obtained Navier-Stokes solutions from DPLR were not fully converged. The surface convective heat flux at approximately $20 \mathrm{~s}$ is assumed to be equal to $1 \mathrm{~W} / \mathrm{cm}^{2}$, and that between 20 and $35 \mathrm{~s}$ is estimated by linear interpolation. 3dFIAT starts the material response simulation at $\mathrm{t}=0$ $\mathrm{s}$, and is not coupled with DPLR and NEQAIR to exchange interface boundary conditions until $35 \mathrm{~s}$. Implicit coupling approach is used starting from $35 \mathrm{~s}$ and ending at $100 \mathrm{sec}$. The time step size for implicit coupling, $\Delta \mathrm{t}_{\mathrm{D}}$, is set to a constant of $1 \mathrm{~s}$. In other words, every one second the interface boundary conditions between gas and carbon surface have to be updated implicitly. It usually requires 3 to 5 internal iterations to converge.

The predicted stagnation point heating history is shown in Fig. 9a. The maximum hot wall ablating convective heat flux is about $600 \mathrm{~W} / \mathrm{cm}^{2}$ and the maximum radiation is about $90 \mathrm{~W} / \mathrm{cm}^{2}$. Both convective and radiative heat fluxes at the stagnation point predicted by Olynick (symbols) are also presented in the same chart for comparison. Olynick's convective heat flux is about $11 \%$ higher than that predicted by current DPLR/3dFIAT simulation system. The bifurcation diffusion model and chemical equilibrium surface assumption adopted in Olynick's work tend to predict higher mass diffusion rate, and surface heat flux. The non-ablating cold wall heat flux (dashed line) is also shown in this chart. The maximum convective cold wall heat flux is slightly above $900 \mathrm{~W} / \mathrm{cm}^{2}$. The stagnation point mass injection rates (solid lines) and surface temperature (dashed line) histories are presented in Fig. 9b. The maximum char mass injection rate is slightly above $0.05 \mathrm{~kg} / \mathrm{m}^{2}$-s. The predicted maximum char mass injection rate in Olynick's work is approximately $0.08 \mathrm{~kg} / \mathrm{m}^{2}$-s. The pyrolysis gas injection rate remains fairly uniform for a long period during the trajectory, and the maximum value is near $0.01 \mathrm{~kg} / \mathrm{m}^{2}-\mathrm{s}$. The predicted maximum surface temperature reaches about $3300 \mathrm{~K}$ at the peak convective heating point.

Figures $10 \mathrm{a}$ and $10 \mathrm{~b}$ show the convective and radiative heat fluxes along the fore-body surface at $\mathrm{t}=40,50,56$, 62 , and $72 \mathrm{~s}$. The heating distributions are similar for all these time points. The maximum heating is located at the stagnation point, a sharp decline on surface heating is observed across the junction between sphere and cone, and a spike occurs along the surface of heat-shield corner. The peak radiative heating occurs at around $t=50 \mathrm{~s}$, which is not at the same time as that of peak convective heating.

Char and pyrolysis mass injection rates along fore-body surface at time points equal to 56 and $72 \mathrm{~s}$ are shown in Figs. 11a and 11b, respectively. The distribution of mass injection rate of pyrolysis gas shown in Fig. 11a appears to be fairly uniform over most of the sphere-cone surface except at the corner region. The char mass injection rate declines rapidly along the spherical section, and then declines moderately in the conical section, as shown in Fig. $11 \mathrm{~b}$.

Figures $12 \mathrm{a}$ and $12 \mathrm{~b}$ present species mass fractions along stagnation stream line at two time points, 56 and $72 \mathrm{~s}$. At $56 \mathrm{~s}$, the free stream enthalpy is high enough to fully dissociate nitrogen molecules within the shock layer. At 76 $\mathrm{s}$, the dissociation rate of nitrogen molecules is very low because of much lower total free stream enthalpy compared with that of $56 \mathrm{~s}$. The major ablation product is $\mathrm{CO}$ at both time points. At $56 \mathrm{~s}$, the carbon surface is in the low sublimation region. Thus, the second most abundant ablation product is $\mathrm{C}_{3}$. The third one is hydrogen atom and the 
forth one is hydrogen molecule. At $72 \mathrm{~s}$, the second most abundant ablation product is $\mathrm{H}_{2}$, which is coming from pyrolysis gas, and the $\mathrm{H}$ mass fraction is one order of magnitude lower than $\mathrm{H}_{2}$. The $\mathrm{C}_{3}$ mass fraction is very low, because the carbon surface reaction is in the regime of diffusion controlled oxidation.

Figure 13 presents the stagnation point recession history. The predicted total recession is approximately $7 \mathrm{~mm}$ at $100 \mathrm{~s}$, which is about $33 \%$ less than that predicted using the chemical equilibrium surface assumption described in Olynick's paper. The post flight measurement of surface recession at the stagnation point is around $6 \mathrm{~mm}$. The stagnation point recession is still over-predicted by about $16 \%$ by using current finite-rate coupled simulation system. 


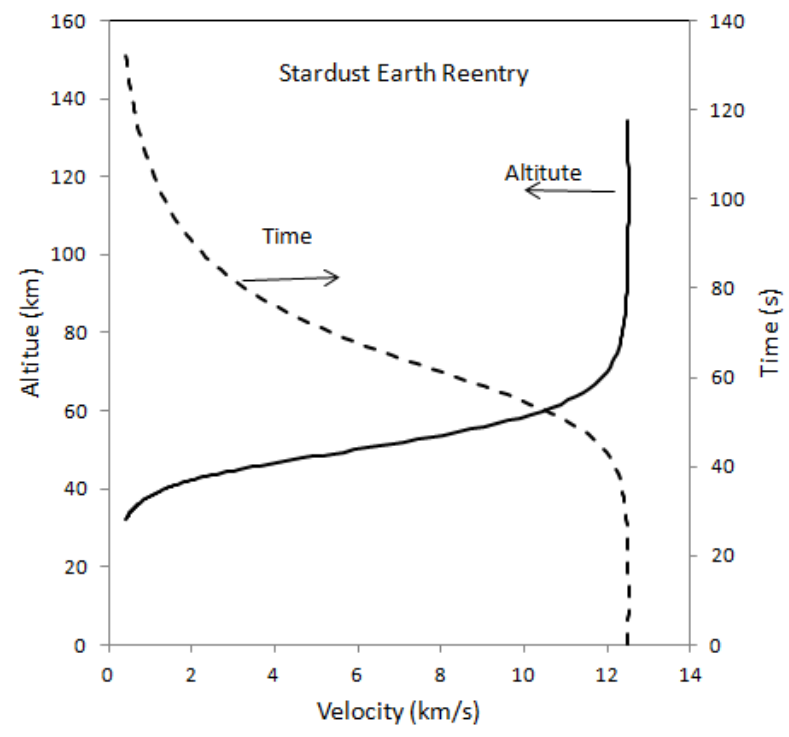

Figure 8 Flight trajectory for the Stardust Earth reentry capsule.

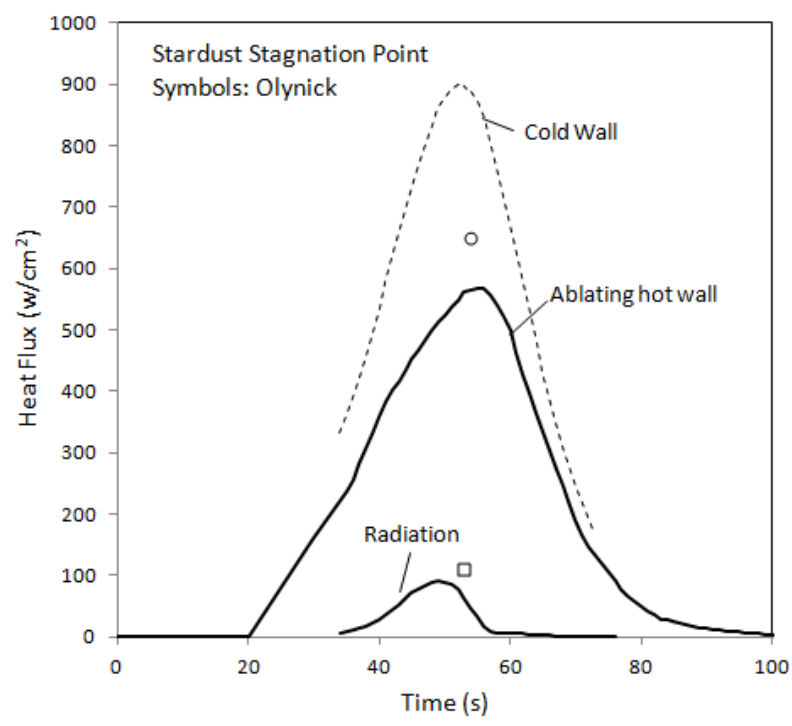

a) Ablating hot-wall convective and radiative heat fluxes.

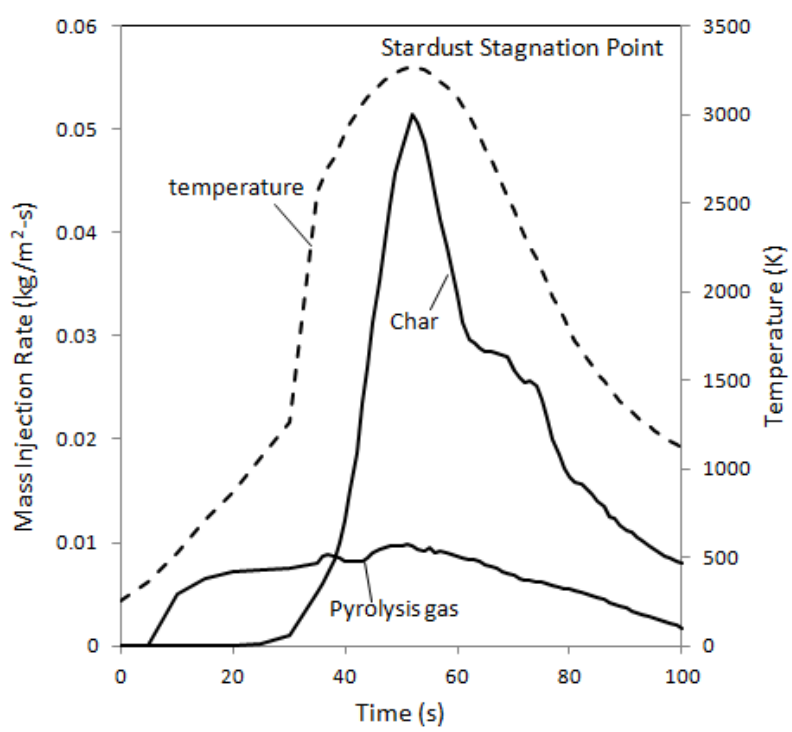

b) Surface temperature and pyrolysis and char mass injection rates.

Figure 9 Computed time history of the stagnation point surface quantities. 


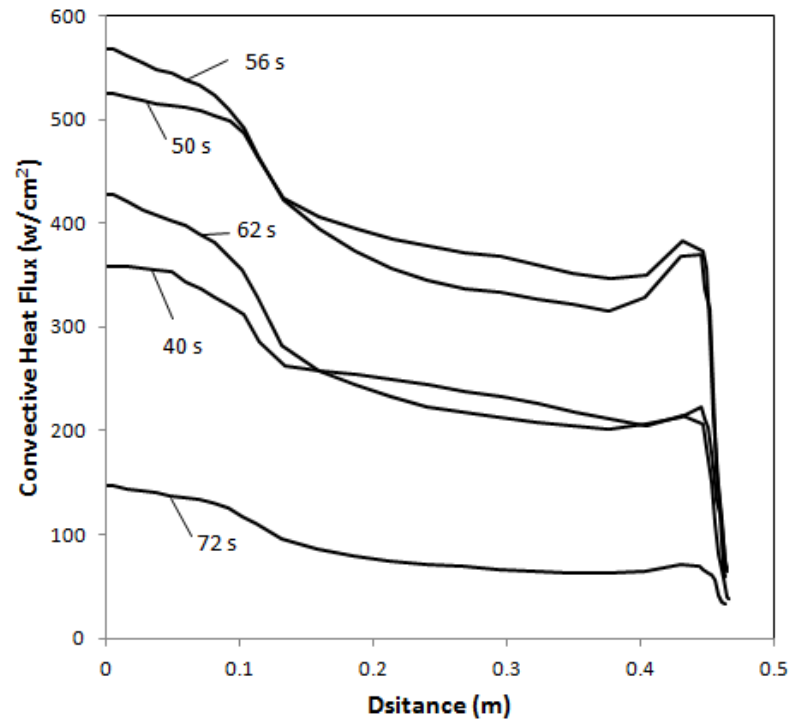

a) Convection

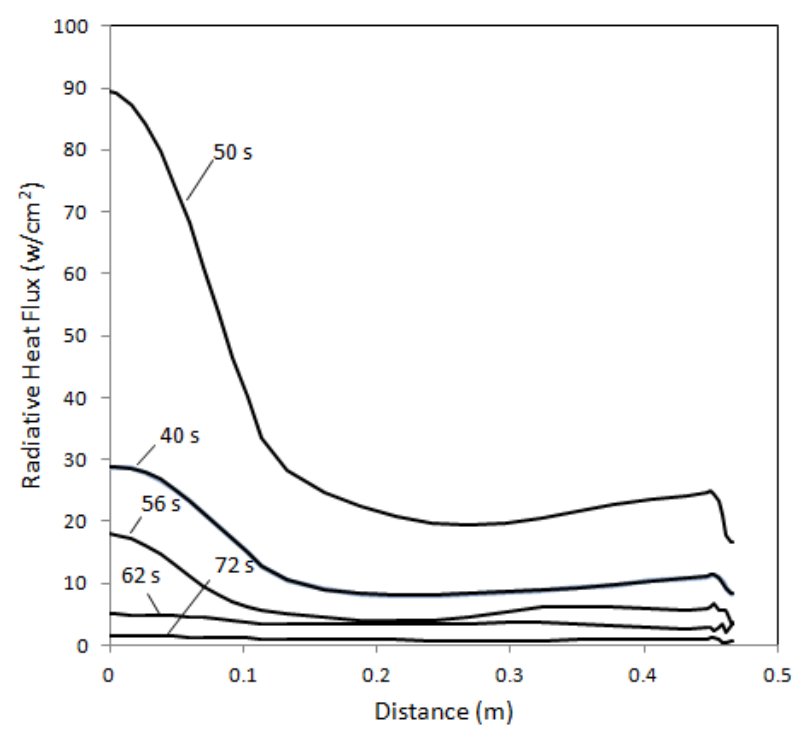

b) Radiation

Figure 10 Heat flux distributions along fore-body heat-shield at various times on the trajectory
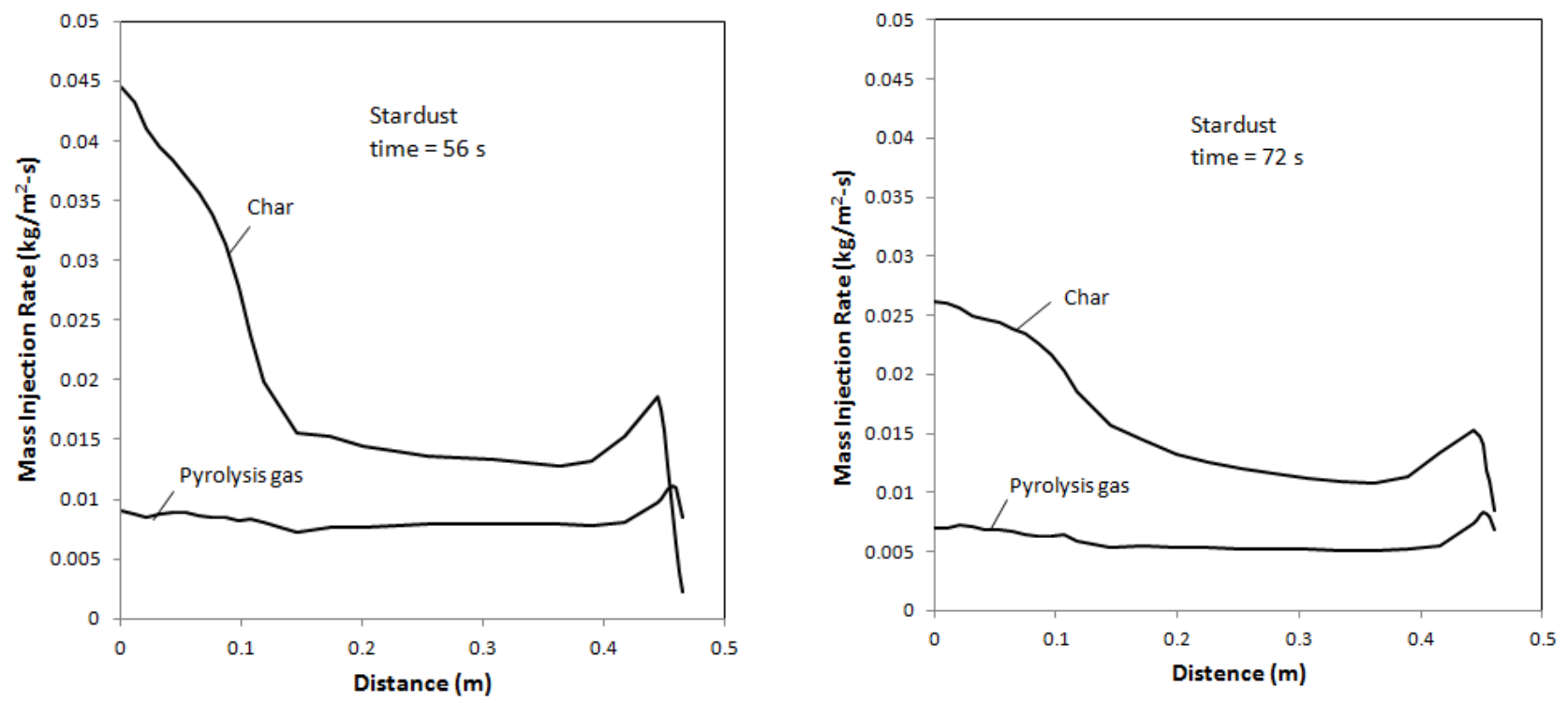

a) $t=56 s$

b) $\mathbf{t}=72 \mathrm{~s}$

Figure 11 Mass injection rate distributions along the fore-body heat-shield at two trajectory points. 

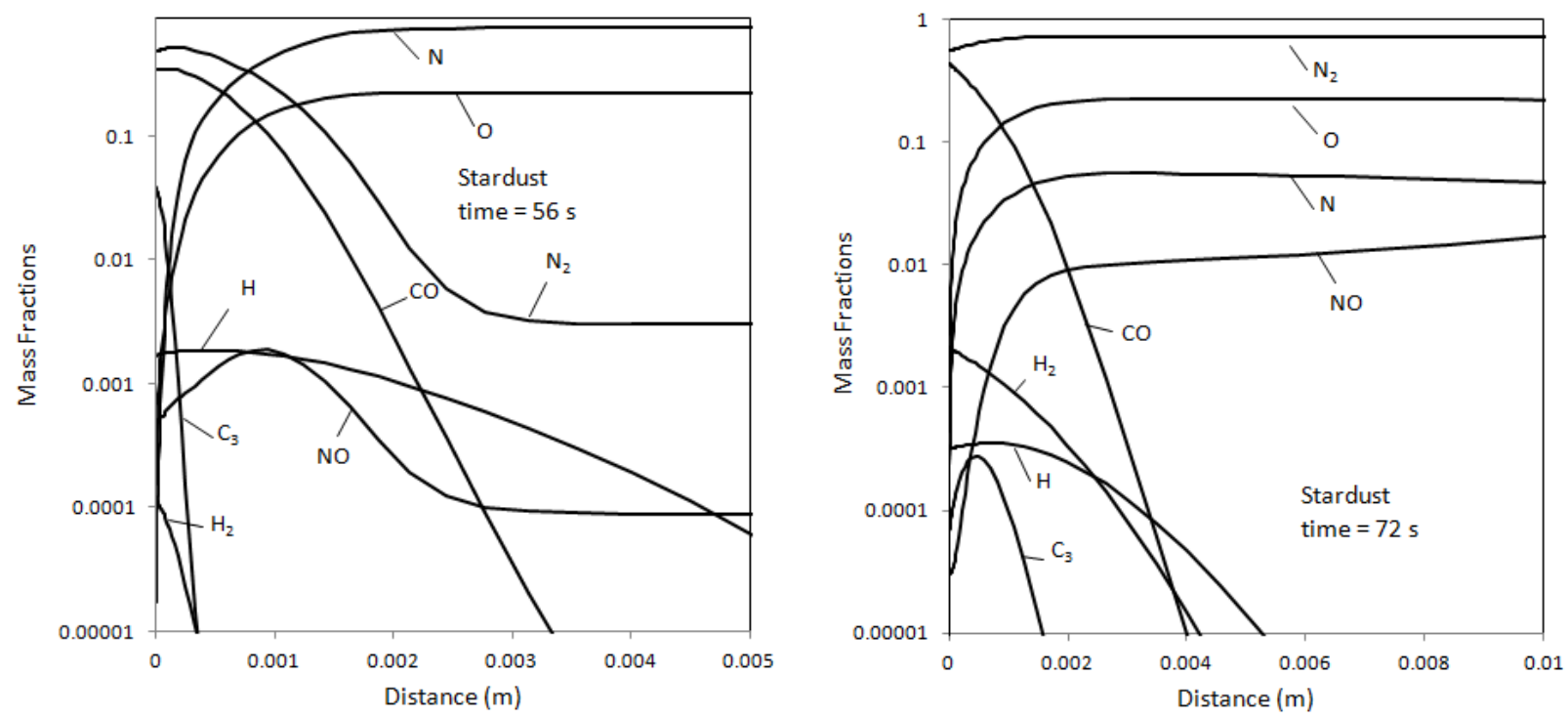

a) $\mathbf{t}=\mathbf{5 6} \mathrm{s}$

b) $72 \mathrm{~s}$

Figure 12 Species mass fractions along the stagnation streamline at two trajectory points

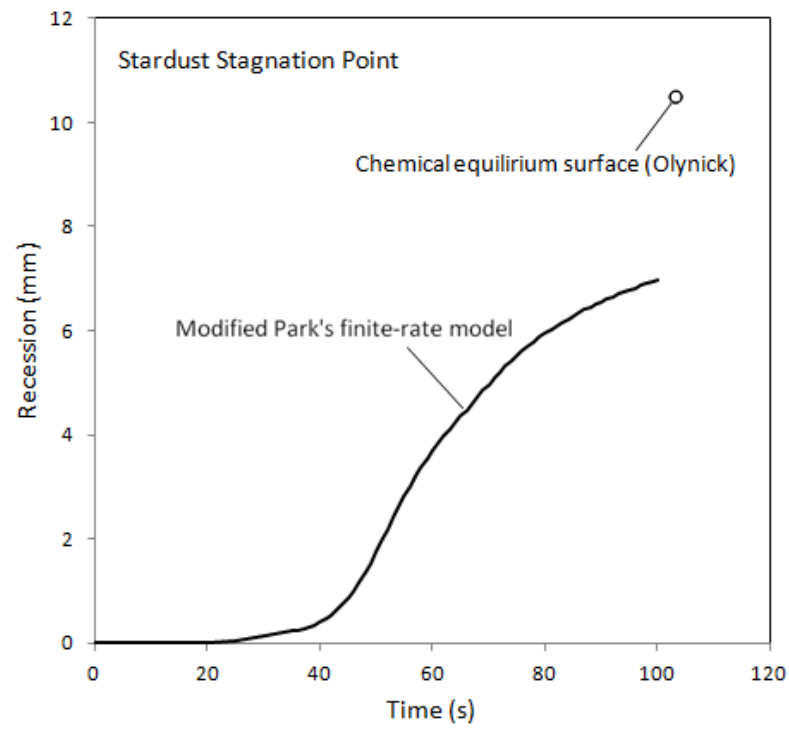

Figure 13 The computed stagnation point total recession as function of time. 


\section{Conclusions}

In this study, coupled simulations of a material thermal response code and a flow solver with non-equilibrium gas/surface interaction for simulation of charring carbon ablators are performed using either implicit or explicit approaches. For analyses of the stagnation tests conducted in NASA Ames Research Center arc-jet facilities both implicit and explicit approaches are used. It is found that the implicit approach is a better approach at the high heating conditions, while the explicit coupling is more time efficient at the lower heating conditions. The implicit approach requires more computational time to complete a single time step for updating the interface boundary conditions due to additional iterations. However, the implicit coupling appears to have no numerical instability issue and does not have any severe numerical oscillations for all seven test conditions. On the other hand, the explicit approach is simpler to construct, but it may require very long run time or fail to converge if excessive numerical oscillations in the predicted surface temperature do occur. The predicted surface recession using the modified Park's model was compared with the experimental measurements at stagnation cold-wall heat fluxes ranging from 107 to $1100 \mathrm{~W} / \mathrm{cm}^{2}$. The maximum difference between predicted recession and arc-jet data is less than $5 \%$.

Trajectory-based simulations for Stardust fore-body heat-shield was also performed using the implicit approach. A constant time step is adopted for this case. The computations using the explicit coupling were not successful because of numerical oscillations around the peak heating point. It is shown that the implicit approach is more appropriate for a trajectory-based surface thermochemistry coupling for Stardust entry. Using the current best available surface chemistry, the predicted stagnation-point heat flux and recession for the Stardust capsule are smaller than those predicted using the chemical equilibrium surface assumption by $11 \%$ and $33 \%$, respectively.

\section{Acknowledgements}

This work is funded by the NASA Fundamental Aeronautics Program under Hypersonics EDL Project.

\section{References}

${ }^{1}$ Chen, Y.-K., Milos, F. S., and Gökçen, T., "Loosely Coupled Simulation for Two-Dimensional Ablation and Shape Change," Journal of Spacecraft and Rockets, Vol. 47, No 5, September-October 2010, pp. 775-785.

${ }^{2}$ Gökçen, T., Chen, Y.-K., Skokova, K. A., and Milos, F. S., "Computational Analysis of Arc-Jet Stagnation Tests Including Ablation and Shape Change," Journal of Thermophysics and Heat Transfer, Vol. 24, No. 4, October-December 2010, pp 694-707

${ }^{3}$ Wright, M. J., Candler, G. V., and Bose, D., "Data-Parallel Line Relaxation Method for the Navier-Stokes Equations," AIAA Journal, Vol. 36, No. 9, Sept. 1998, pp 1603-1609.

${ }^{4}$ Chen, Y.-K., and Milos, F.S., "Two-Dimensional Implicit Thermal Response and Ablation Program for Charring Materials," Journal of Spacecraft and Rockets, Vol. 38, No. 4, 2001, pp. 473-481.

${ }^{5}$ Chen, Y.-K., and Gökçen, T., " Effect of Non-equilibrium Surface Thermochemistry in Simulation of Carbon Based Ablators," AIAA-2012-2747 , 43 ${ }^{\text {rd }}$ AIAA Thermophysics Conference, New Orleans, LA, June 25-28, 2012.

${ }^{6}$ MacLean, M., Marschall, J., and Driver, D., "Finite-Rate Surface Chemistry Model, II: Coupling to Viscous Navier-Stokes Code," AIAA-2011-3784, 42 ${ }^{\text {nd }}$ AIAA Thermophysics Conference, Honolulu, Hawaii, June 27-30, 2011.

${ }^{7}$ Park, C., and Ahn, H. K., "Stagnation-Point Heat Transfer for Pioneer-Venus Probes, " Journal of

Thermophysics and Heat Transfer, Vol. 13, No. 1, January-March 1999, pp. 33-41.

${ }^{8}$ Tran, H., Johnson, C, Rasky, D., Hui, F., Chen, Y.-K., and Hsu, M., "Phenolic Impregnated Carbon Ablators (PICA) for Discovery Class Missions," AIAA Paper 96-1911, 31 ${ }^{\text {st }}$ AIAA Thermophysics Conference, New Orleans, LA, June 17-20, 1996.

${ }^{9}$ Chen, Y.-K., and Milos, F. S., " Navier-Stokes Solutions with Finite-Rate Ablation for Planetary Mission Earth Re-entries," Journal of Spacecraft and Rockets, Vol. 42, No. 6, 2005, pp. 961-970.

${ }^{10}$ Anon., User's Manual: Aerotherm Chemical Equilibrium Computer Program, Acurex Corporation, Aerotherm Division, Mountain View, CA, Aug. 1981.

${ }^{11}$ Milos, F.S., and Chen, Y.-K., "Comprehensive Model for Multi-Component Ablation Thermochemistry," AIAA Paper 97-0141, 35 ${ }^{\text {th }}$ Aerospace Sciences Meeting and Exhibit, Reno, NV, Jan. 6-9, 1997.

${ }^{12}$ Chen, Y.-K., and Milos, F. S., "Effect of Non-equilibrium Chemistry and Darcy-Forchheimer Flow of Pyrolysis Gas for a Charring Ablator," AIAA-2011-3122 , 42 ${ }^{\text {nd }}$ AIAA Thermophysics Conference, Honolulu, Hawaii, June 27-30, 2011.

${ }^{13}$ Zhluktov, S. V. and Abe, T., "Viscous Shock-Layer Simulation of Airflow past Ablating Blunt Body with Carbon Surface, " Journal of Thermophysics and Heat Transfer, Vol. 13, No. 1, January-March 1999, pp. 50-59. 
${ }^{14}$ Marschall, J., and MacLean, M., "Finite-Rate Surface Chemistry Model, I: Formulation and Reaction System Examples," AIAA-2011-3783, 42 ${ }^{\text {nd }}$ AIAA Thermophysics Conference, Honolulu, Hawaii, June 27-30, 2011.

${ }^{15}$ Milos, F. S., and Chen, Y.-K., "Ablation and Thermal Response Property Model Validation for Phenolic Impregnated Carbon Ablator," Journal of Spacecraft and Rockets, Vol. 47, No. 5, 2010, pp. 786-850.

${ }^{16}$ Olynick, D. R., Chen, Y-K, and Tauber, M. E., "Aerothermodynamics of the Stardust Sample Return Capsule, " Journal of Spacecraft and Rockets, Vol. 36, No. 3, May-June 1999, pp. 442-462.

${ }^{17}$ Gökçen, T., "N $\mathrm{N}_{2}-\mathrm{CH}_{4}$-Ar Chemical Kinetic Model for Simulations of Titan Atmosphere Entry," Journal of Thermophysics and Heat Transfer, Vol. 21, No. 1, Jan.-March 2007, pp 9-18.

${ }^{18}$ Kruse, T. and Roth, P., "Kinetics of $\mathrm{C}_{2}$ Reactions during High-Temperature Pyrolysis of Acetylene,"

Journal Physical Chemistry A, 1997, 101, 2138-2146

${ }^{19}$ Park, C., Howe, J.T., Jaffe, R.J., and Candler, G.V. "Review of Chemical-Kinetic Problems of Future NASA Missions, I: Mars Entries," Journal of Thermophysics and Heat Transfer, Vol. 8, No. 1, January 1994, pp. 9-2

${ }^{20}$ Milos, F. S., and Chen, Y.-K., "Ablation and Thermal Response Property Model Validation for Phenolic Impregnated Carbon Ablator," Journal of Spacecraft and Rockets, Vol. 47, No. 5, 2010, pp. 786-850.

${ }^{21}$ Whiting, E E, Park, C, Liu, Y, Arnold, J O, and Paterson, J A, NEQAIR96, Nonequilibrium and Equilibrium Radiative Transport and Spectra Program: User's Manual, NASA RP-1389, NASA, December 1996.

${ }^{22}$ Desai, P., Qualls, G., and Levit, C., "Stardust Entry Reconstruction," AIAA Paper 2008-1198, $46^{\text {th }}$ AIAA Aerospace Sciences Meeting and Exhibit, Reno, NV, Jan. 2008.

${ }^{23}$ Chen, Y.-K., and Milos, F.S., "Ablation and Thermal Analysis Program for Spacecraft Heatshield Analysis," Journal of Spacecraft and Rockets, Vol. 36, No. 3, 1999, pp. 475-483.

${ }^{24}$ Olynick, D. R., Henline, W. D., Chamber, L. H., and Candler, G. V., "Comparisons of Coupled Radiative Flow Solutions with Project Fire II Flight Data, " Journal of Thermophysics and Heat Transfer, Vol. 9, No. 4, 1995, pp. 586-594. 